devoted to " the Contagious Diseases Acts." I think that a careful study of the facts enumerated therein should carry conviction to all unbiassed minds as to the sanitary benefits which the enforcement of the Acts conferred upor. those districts in which they were operative. Mr. Burney seems to think that "a mental myopia" is the necessary corollary of special training, whatever that phrase may mean. But I can assure him that no such a curriculum is necessary to enable the average medical mind to recognise the farreaching effects of venereal disease upon the population. Medical students, as a rule, recognise the ubiquity and gravity of these maladies by the time they have finished their clerking and dressing. For their ravages are constantly to be noted in every department of mericine and surgery-a fact whicb, I think, is admitted by everyone having an intimate knowledge of general hoskital practice. Syphilis is a malady which may be said to be antagonistic to any rigid specialism, for it impartially invades the quasispecial provinces of eye, ear, throat, nose, skin, children, and nerves with the same freedom as that with which it assails the realms of gynæcology or general medicine and surgery. Perchance Mr. Burney regards the evolution of such conditions as cancer of the tongue, necrosis of bones, paralysis, panophthalmitis, iridocyclitis, aneurysm, salpingitis, sterility, lunacy, surgical kidney, and the many other seque' $x$ of venereal disorders as unworthy of preventative medico-legal consideration, since be scathingly resents "being gravely told of the fearful perils of the streets," and apparently objects to any "rigorous measures being demanded to check its progress by State interference." If the above is not a grave indictment I cannot well imagine what he would call one.

The Contagious Diseases Acts certainly restricted disease in this country, notwithstanding all the disparaging comparisons of continental failure which may be brought against them. Personally, I would be the first to admit that these Acts required improvement as to their working, for many deplorably unfortunate incidents arose through the method of their enforcement. One would imagine that it is possible to devise some plan of official supervision of subordinates which would curb the irresponsibility of individual denouncing power. As regards the interference with the liberty of the subject I fail to see much difference between consigning a small-pox patient who is carried off to a hospital whether he likes it or no to immunising a prostitute for the purpose of curing her of venereal disease. Mr. Burney need only think of the interference and inquisition of the Income Tax to see that the State regulation of one's life and private affairs is not a legal novelty. Allow me to say that if one is to expect really good effects from a Contagious Diseases Act it is requisite for it to be general tbroughout the country and not to restrict its operations to a few chosen localities; for therein lies the certainty of failure. I think Mr. Burney will admit that the Contagious Diseases Acts were not repealed upon the action of the medical profession as a body.

$$
\text { Feb. 2rth, 1503. I am, Sirs, yours faithfully, }
$$

\section{THE TURVEY TREATMENT COMPANY (1905), LTD.}

To the Editors of THE LANCET.

SIRs,-In a letter published by you in your issue of Feb. 24th from the solicitor to the Turvey Treatment Company, Ltd., I note the following passage: “...... at the same time my clients challenge you to point out any one case where anyone has been treated by their methods which has not been successful."

Lest any of your numerous readers may be deceived by this ridiculous claim to infallibility may $\mathbf{I}$ be permitted to bear witness to one striking failure? At the earnest request of his relatives I consented to try the Turvey treatment upon a patient of mine who had been an inebriate for some years. The conditions were exceptionally favourable to the success of the treatment, as the patient was at the time laid up in my Home suffering from paresis of the legs and was in consequence absolutely under control. The treatment was carried out under my personal supervision in exact accordance with the directions issued by the proprietors of the Turvey treatment, not a single dose being missed, and every possible help being given in the way of diet, skilled nursing, and massage. The result, however, was an absolute failure; within a few hours of regaining his liberty the patient was drinking as heavily as ever and continued to do so until the neuritis reiurned and he again lost the use of his leg!. I did not trouble to report the result to the Turvey Co., so possibly they added this case to their list of "cures." I am, Sirs, yours faithfully,

Harley-street, W., Feb. 23rd, 1906. J. HeNRY ChaLdeCoTt'.

\section{INDECENT PUBLICITY: A REPUDIATION.} To the Editors of THE LANCET.

SIRs,-We desire to repudiate together and individually all responsibility for the use made of our names and our report in an account of certain lunacy proceedings published in the Daily Mail of Saturday, Feb. 24th, and subsequently reproduced in other periodicals.

We are, Sirs, yours faithfully,

ROBERT JONES.

Thos. D. Lister.

Feb. 25th, 1906.

\section{THE DISEASES OF CHILDREN.}

To the Editors of THE LANCET.

SIRs,- In your issue of Feb. 24th in a review of the fifth edition of the above work by Dr. H. Ashby and Mr. G. A. Wright it is remarked that infantilism or ateleiosis has escaped notice by the writers. May I, while cordially thanking your reviewer for his kindly notice of our book, point out that Chapter XXXIV., p. 795 , contains a brief account of this subject though it has been omitted from the index. I Im, Sirs, yours faithfully,

Westbrook, Bowdon, Cheshire, Feb. 27th, 1906. G. A. Wright.

\section{THE VALUE OF SANATORIUMS AND THE ORGANISED TREATMENT OF PUL- MONARY TUBERCULOSIS. \\ To the Editors of THE LANCET.}

SIRS,-Sir William Broadbent concluded his interesting memorial to the Metropolitan Asylums Board on the question of pulmonary tuberculosis with a brit $\mathrm{f}$ statement of certain views current about the value of sanatoriums in the treatment and prevention of that disease. The very important series of papers on this subject, which appeared in THE LANCET of Jan. 6th, must have brought home to all who read them the conviction that sanatoriums have disappointed many of the hopes which at first were entertained concerning them by large sections of the public, among whom there has even, perhaps, been too considerab?e a reaction. It seems certain that a large proportion of cases in an early stage of pulmonary tuberculosis, but unhindered by special constitutional weakness or complications will admit of cure in sanatoriums if they will submit to the necessary discipline and persevere for the necessary time; but the fulfilment of these conditions is only possible in a limited number of instances and is practically impossible for the enormous majority of the poor. The phthisical poor of ten derive great temporary benefit from hospital treatment, but as soon as they return to their former domestic conditions they rapidly fall back into their former state.

It is doubtful whether the supposed diminution of infection arising from precautions with regard to sputa can at present be said to take rank as a scientific truth. The suggestion was first strongly pressed in connexion with Professor Koch's denial of the identity of bovine with human tuberculosis. That denial, and the doubt thrown by it upon the dangers to the human subject arising from diseased animals, was the immediate occasion of the Royal Commission under Sir Michael Foster, which, in an interim report, speedily furnished evidence that Professor Koch had been in error. This Commission has since been continuously engaged in the further investigation of the subject, and especially in endeavours to determine the consequences of the consumption of the milk furnished by tuberculous cows. It is, of course, quite possible that pulmonary tuberculosis may be communicated through the agency of human sputa. As Faraday used to say with regard to any doubtful scientific question, "it may be so," but it cannot be said that any evidence in excess of probability has as yet been furnished in support of the suggestion. In such circumstances it is obviously right to use all practicable precautions, but it is not right to treat as a fact what is at 